\title{
Investigation of KPP-5 Rail Fastener Elastic Deformation
}

\author{
R. V. Markul ${ }^{1}$, N. P. Nastechik ${ }^{1}$, V. V. Kovalchuk ${ }^{2}$ and Y. M. Hnativ ${ }^{3}$ \\ ${ }^{1}$ Department of Track and Track Facilities, Dnipropetrovsk National University of \\ Railway Transport named after Academician V. Lazaryan 2, Lazaryan str., Dnipro, \\ Ukraine, 49010 \\ *Email: guarangamr@gmail.com \\ ${ }^{2}$ Department of Rolling Stock and Track, Lviv branch of Dnipropetrovsk National \\ University of Railway Transport named after Academician V. Lazaryan 12a, \\ Blazhkevych str, Lviv, Ukraine, 79052 \\ ${ }^{3}$ Department of Transport Technologies, Lviv branch of Dnipropetrovsk National \\ University of Railway Transport named after Academician V. Lazaryan 12a, \\ Blazhkevych str., Lviv, Ukraine, 79052
}

\begin{abstract}
For a long period of operation, a number of shortcomings have been identified in KPP-5 fastener that is mainly due to an intensive decrease of pressing force of the rail on sleepers. This leads to the appearance of frequent cases of track displacement and fastening elements failure. To verify such hypothesis, the process of power work of KPP-5 fastener during railway track operation was researched. The technique and practical means of controlling the power work of KPP-5 fastener are developed. The influence of various factors of the rail pressing force on the sleeper is determined. The main influence is conditioned by under-rail wear $(50.4 \%)$. The obtained results made it possible to formulate recommendations for the improvement of KPP-5 fastener where the methodology and practical means of controlling the power work of KPP-5 fastener were proposed. At the same time, it allows increasing the reliability and safety of the rail track during the entire overhaul period.
\end{abstract}

Keywords: Rail track; rail fastener; pressing force; elastic deformation; KPP-5.

\section{INTRODUCTION}

One of the strategic tasks related to the introduction of high-speed train traffic is to ensure reliable operation of rail fasteners. The common type of fasteners operating on the railways of Ukraine [1], Poland [2], Byelorussia [3], Kazakhstan [4] is KPP-5 fastener as shown in Figure 1. About 5 thousand $\mathrm{km}$ of main railways have been laid on the territory of Ukraine. This type of fastener is the prototype of Polish rail fastener SB-3.

The KPP-5 rail fastener has some advantages at the initial stage of operation. These advantages are easy installation and dismantling of the railway components; absence of threaded connections; a small quantity of parts (only seven parts and none with a thread); low metal consumption $(\approx 5 \mathrm{~kg})$. But after a long period of operation of KPP-5 fastener, a number of shortcomings have been identified. They are mainly due to the intensive decrease of pressing force of the rail on the support (sleepers) [1]. Initially, this problem arose at Odessa Railway (Ukraine), when non-abutment rails displacement took place while this type of fastener was used. At present, KPP-5 fastener is replaced by a new one, when any of its elements are out of order as they are not subject to repair [1]. 


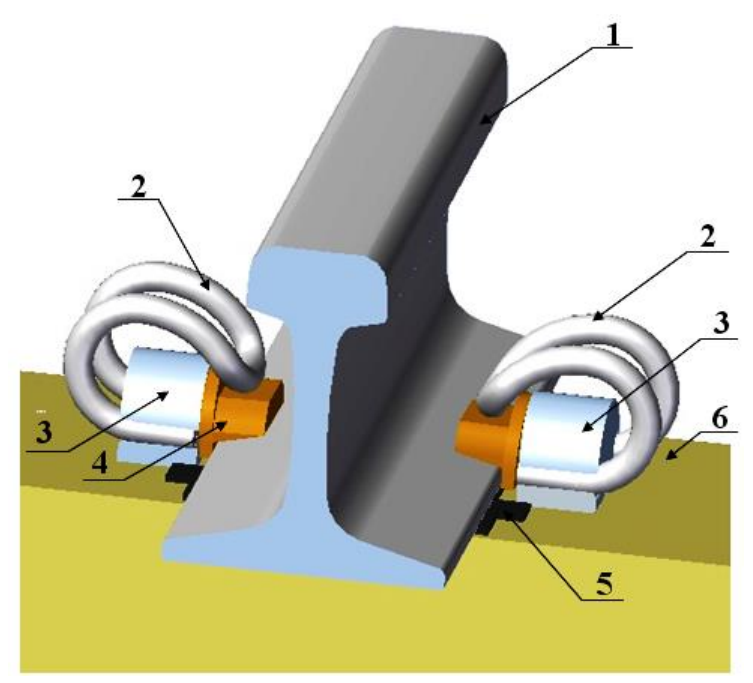

Figure 1. The arrangement of KPP-5 fastener: 1 - rail, 2 - elastic terminal KP-5.2; 3 anchor, 4 - polymer inserter VIP, 5 -underrail gasket PRP-2.1; 6 - sleeper SB3-0.

The resistance of the rail to the longitudinal movement depends on many factors: basically, on the constant provision of pressing force on the rail by terminals during the overhaul period. According to studies [5], the terminal KP-5.2 should ensure minimal rail pressing force by $10 \mathrm{kN}$. Spring terminals must provide the standard mounting pressure of the rail on each under-rail support with the force of $20 \mathrm{kN}$ since they ensure the reliability of the fastener assembly as a whole [6]. Partly, this is due to the elastic operation of the terminal. However, during operation, it is expected a certain decrease in the pressing force of the terminal on the rail due to the loss of its elastic properties [7]. After pressing force decrease, the stability of the spatial rigidity of the fastener and the elastic transmission of the dynamic action of the wheels of the rolling stock onto the rails are being lost [8]. This leads to the appearance of defects [9], and the accelerated process of damage to the elements of the upper structure of the rail track [10]. The reduction in the power work of the spring terminal depending on the passed tonnage has not been thoroughly researched. To date, the pressing force of the terminal on the rail during operation remains uncontrolled in KPP-5 fastener. In future, this can adversely affect the operation of other elements in KPP-5 fastener and lead to the loss of its performance.

There is a problem connected with the lack of methodology and practical means of monitoring the state of the power work of KPP-5 fastener. Above mentioned problem solution allows increasing of the efficiency of KPP-5 fastener used. The paper aims to study the power work of KPP-5 fastener in the process of railway track operation by the criteria of traffic safety. In order to achieve the goal, it is necessary to investigate and substantiate the influence of various factors on the strength work of the fastener KPP-5 during operation, while providing recommendations for improving the reliability of the strength work of the fastener KPP-5.

\section{EVALUATION OF FACTORS INFLUENCING RAIL PRESSING FORCE OF KPP-5 FASTENER ON THE UNDER-RAIL AREA}

The elastic deformation of the terminal of KPP-5 fastener depends on the distances of the axis of the holes and grooves of the anchor relative to the under-rail area of reinforced 
concrete sleepers after their building it. The schematic diagram for measuring the distance of the anchor hole relative to the under-rail area of SB3-0 sleeper is shown in Figure 2.

From the analysed the data [1], it was found that the value of elastic deformation of the terminal during installation into the working position varies between $11 . .15 \mathrm{~mm}$, the average value of which is $13 \mathrm{~mm}$. In this case, the value of pressing mounting force by the range of values of elastic deformation $(11 \ldots 15 \mathrm{~mm})$ will be $\mathrm{P}_{0}=13.58 \ldots 19.54$ $\mathrm{kN}$. The average value of pressing mounting force of the new rail by the terminal on under-rail basis is $\mathrm{P}_{0}=16.56 \mathrm{kN}$.

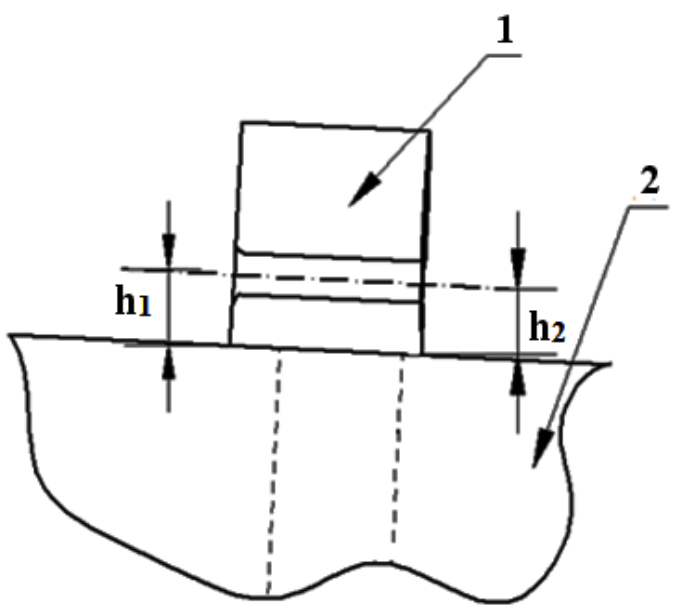

Figure 2. A schematic of measuring axial distances of the anchor hole and groove relative to the under-rail area of the sleeper with 1 - anchor; 2 - sleeper SB3-0.

\section{Terminal Elasticity}

Studies of elasticity of KP-5.2 terminal were carried out using the tracking device developed by the Dnepropetrovsk National University of Railway Transport named after academician V. Lazaryan (from now on referred to as DNURT) for measuring the force of terminal pressing on the rail in case of KPP-5 fastener use [11]. With the help of this tracking device, the force of terminal pressing on the rail was determined using evaluation of elastic properties of the terminal.

In 2015 the maximum passed tonnage on the section of the railway, where KPP-5 fastener operated, was 447 million tons gross. Accordingly, the analysed stiffness values (Stiffness, $\mathrm{kN} / \mathrm{mm})$ and the pressing force of the terminal on the rail $(\Delta \mathrm{Pt}, \mathrm{kN})$ depending passed tonnage of 447 million tons gross were decreasing that was predictable (dashed line). The obtained results during the entire overhaul life are shown in Figures 3 and Figure 4.

According to Figure 4, at the initial stages of operation the pressing force of the rail with the elastic terminal on the under-rail basis has been less than the normative one, that is the minimum permissible value [1]. For more detailed evaluation of the power work of elastic terminals, the studies were carried out to determine the elastic deformation of the terminal depending the technological process "assembly-dismantling". 


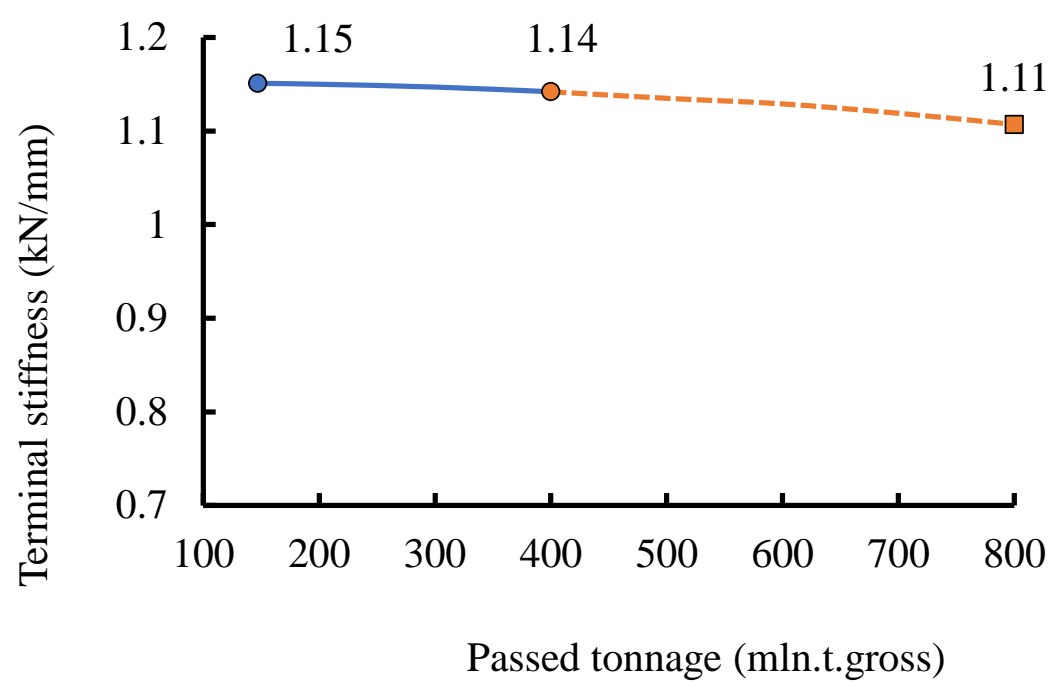

Figure 3. Terminal stiffness changes depending on passed tonnage.

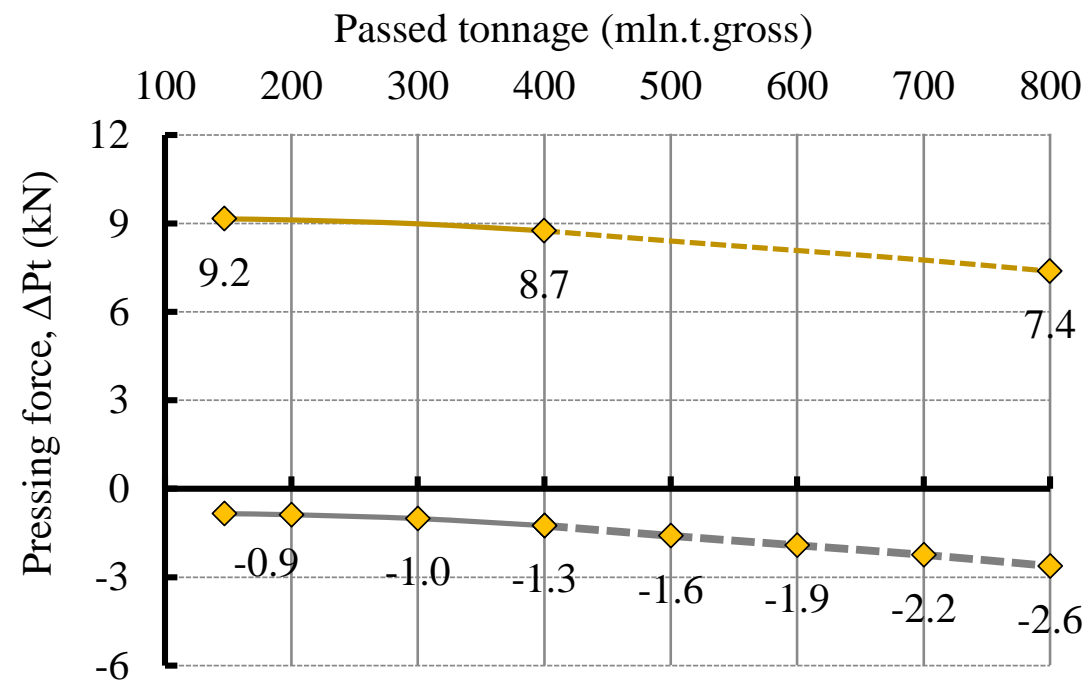

Figure 4. Reduction (-) and change of pressing force of the rail on under-rail basis depending on terminal weakening.

\section{Elastic Deformation of Terminal}

The studies consisted of the analysis of elastic deformation of terminals in the multi-cycle process of terminal assembly-dismantling. Elastic deformation of the terminal was measured between VIP insulating insert and the rail foot in the area of their contact using an automobile probe at the working position of the track device [11]. The measurement scheme is shown in Figure 5. 


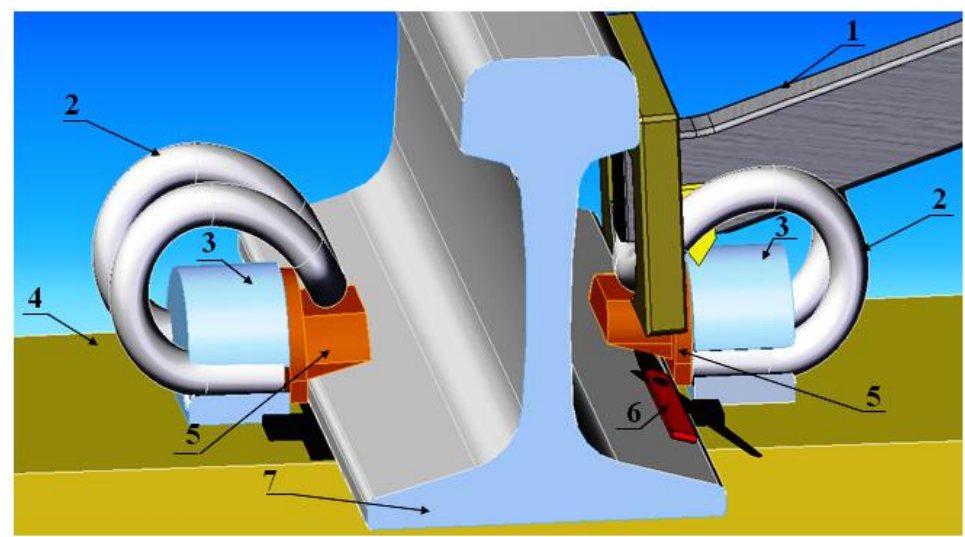

Figure 5. The measurement scheme of the elastic deformation of the terminal in KPP-5 rail fastener: 1 - rail device; 2 - elastic terminal KP-5.2; 3 - anchor; 4 - sleeper SB3-0; 5 - polymer insert VIP; 6 - measuring probe; 7 - rail.

The results of the dependence of the elastic deformation of the terminal on the number of "assembly-dismantling" cycles are given in Figure 6. The nature of the change in the elastic deformation of the terminal is non-linear and is described by the function in Eq. (1).

$\mathrm{y}_{\mathrm{i}}=0.0009 \mathrm{x}_{\mathrm{i}}^{3}-0.025 \mathrm{x}_{\mathrm{i}}^{2}+0.2722 \mathrm{x}_{\mathrm{i}}-0.2381$,

where $y_{i}$ coordinates of the measured $i$-th point (elastic deformation of the terminal, $\mathrm{mm}$ ), $x_{i}$ is the serial number of the "assembly-dismantling" performance of the terminal.

Putting the values of the serial number of the assembly- dismantling performance in Eq. (1), we obtain the value of the coordinate $y_{i}$ (change of the value of the elastic deformation of the terminal). The results of the change in the pressing force, depending on the number of assembly-dismantling cycles, is shown in Figure 7.

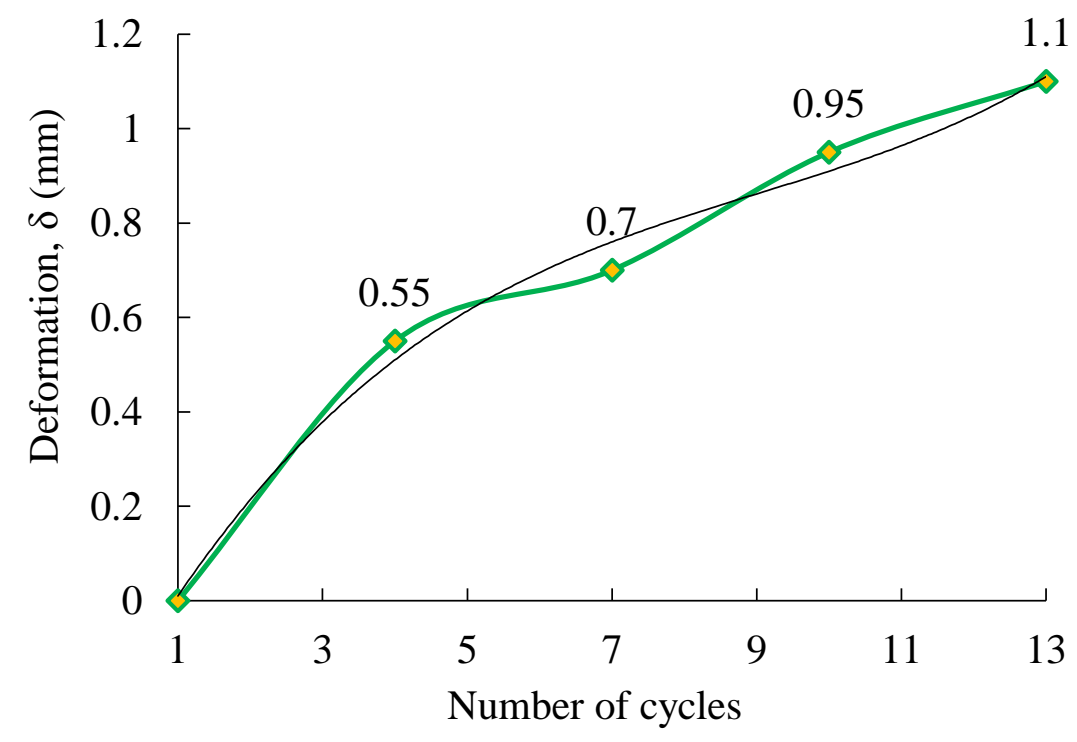

Figure 6. Changes in elastic deformation of KP-5.2 terminal depending on the number of assembly-dismantling cycles. 


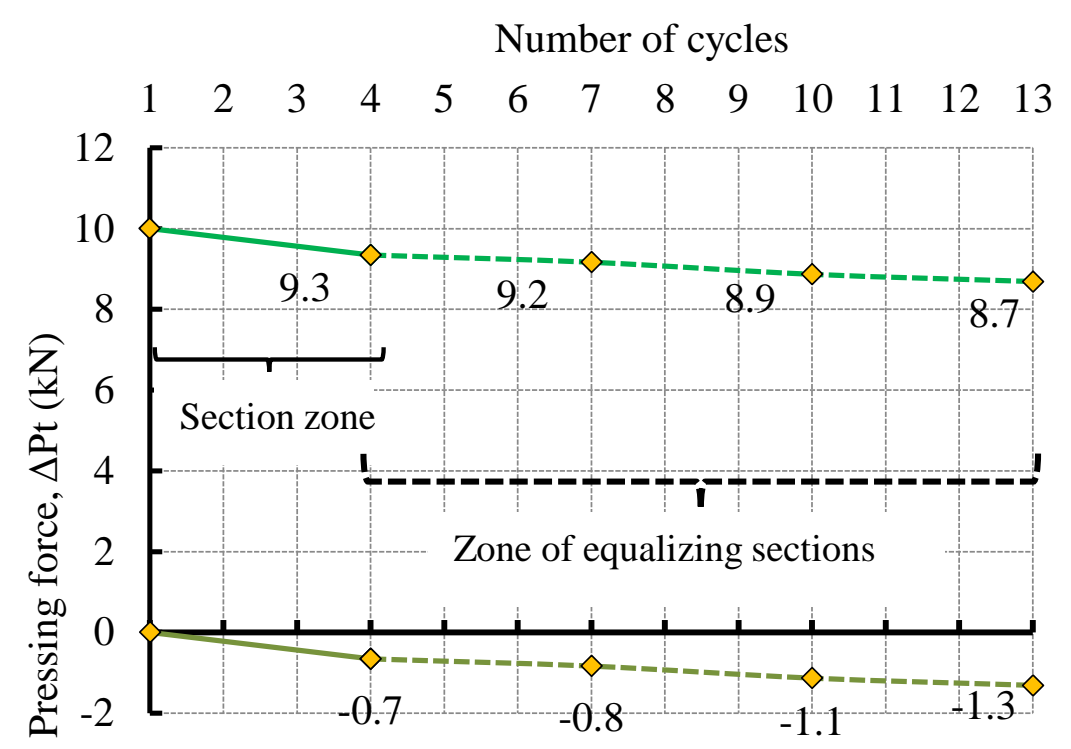

Figure 7. Decrease (-) and change of pressing force of the rail on the under-rail basis, depending on the number of assembly-dismantling cycles of the terminal.

According to Figure 7, it is possible to predict that the number of assemblydismantling cycles of the terminal in the zone of equalising sections is greater, which affects the decrease of the pressing force of the rail on the under-rail basis.

\section{Analysis of Residual Deformations}

The investigations of residual deformations were carried out on existing under-rail gaskets PRP-2.1 (Ukraine). The transverse profile of the new PRP-2.1 gasket has the form of a sinusoidal curve with a variable arrangement of the corrugations (convexities) over its entire area, as shown in Figure 8.

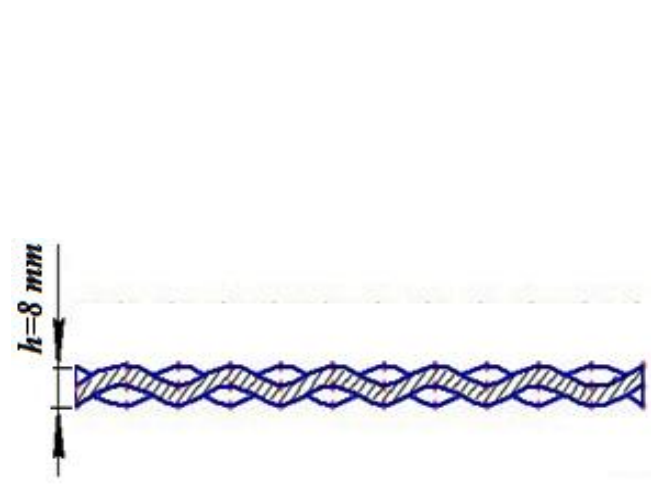

(a)

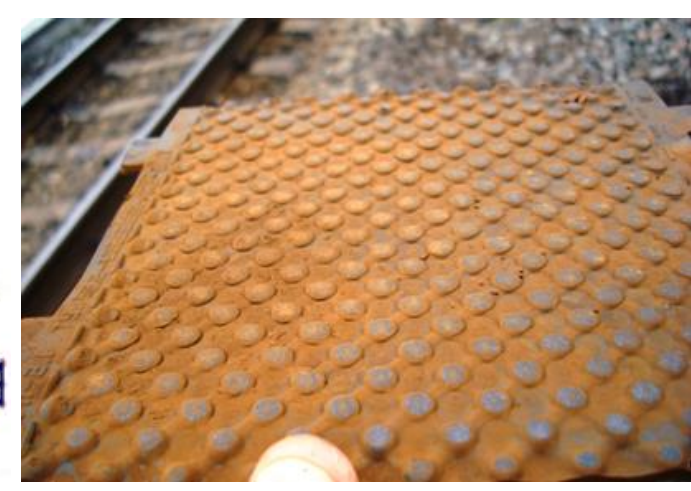

(b)

Figure 8. The transverse profile (a) and the general view (b) of PRP-2.1 gasket.

It was found that with a passed tonnage of 440 million tons gross the thickness of the gasket decreases for almost $50 \%$. After $\mathrm{T}=440$ million tons gross passage and to the end of the overhaul period, the gasket works as a hard stamp. The experimentally obtained average values of residual deformation of PRP-2.1 under-rail gasket is shown in Figure 9. 


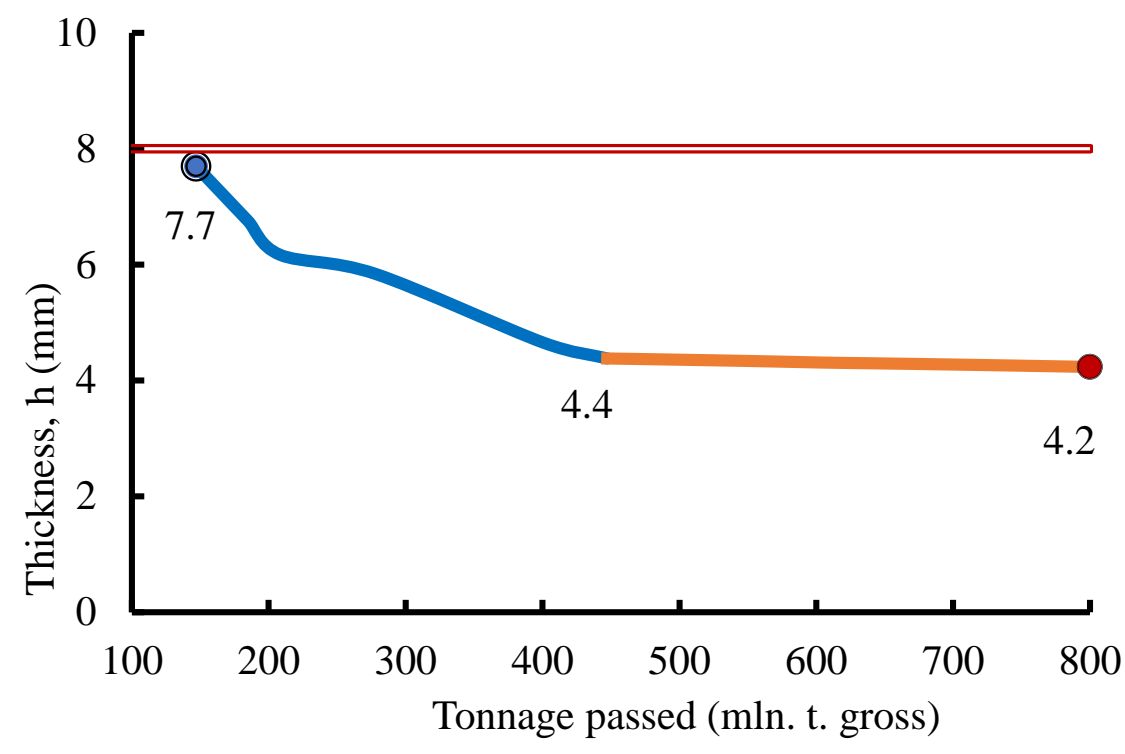

Figure 9. Change of thickness of PRP -2.1 gaskets depending on tonnage passed.

The thickness of under-rail gasket PRP-2.1 during operation reduced due to the crushing of ridges on the gasket surface (as in Figure 9). The impact of the residual deformation of the gasket on the change and decrease of the rail pressing force on underrail basis during the entire service life is shown in Figure 10.

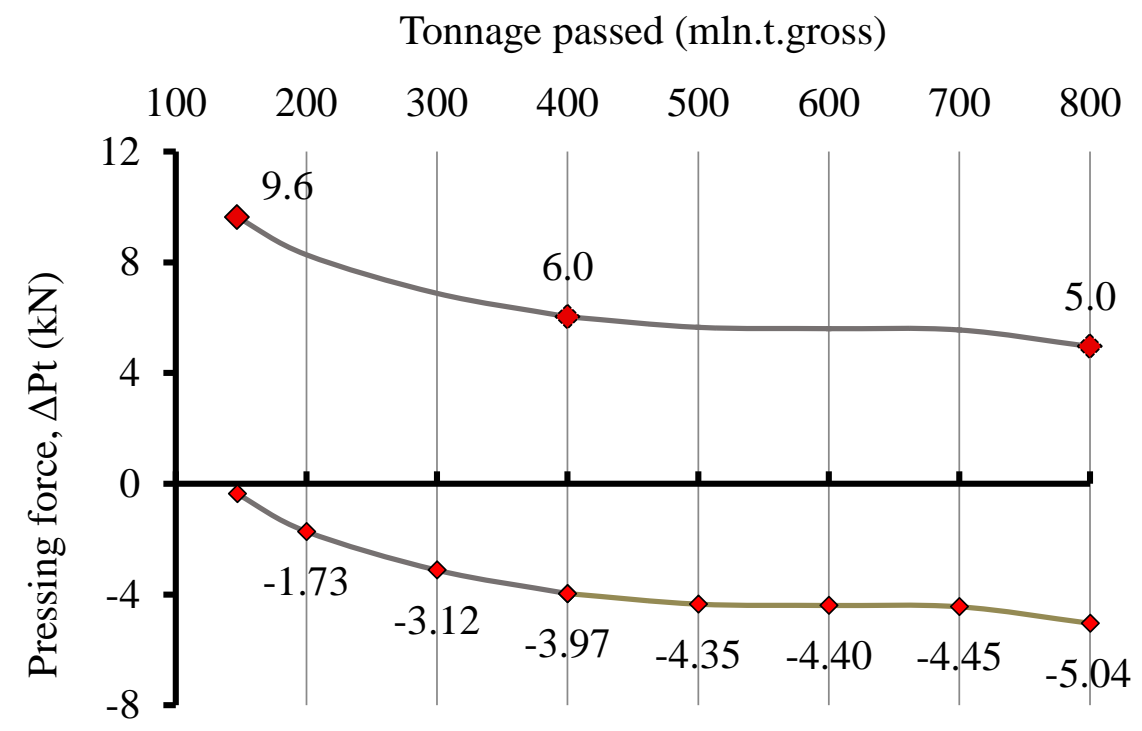

Figure 10. Reduction (-) and change in the pressing force of the rail depending on the wear of PRP-2.1 gasket including forecasting.

The reliability of the under-rail gasket operation depends not only on the material but also on its design. Taking into account the dependence of the pressing force of the rail on the sleeper with KPP-5 fastener use, its impact was determined in the percentage as shown in Figure 11. 


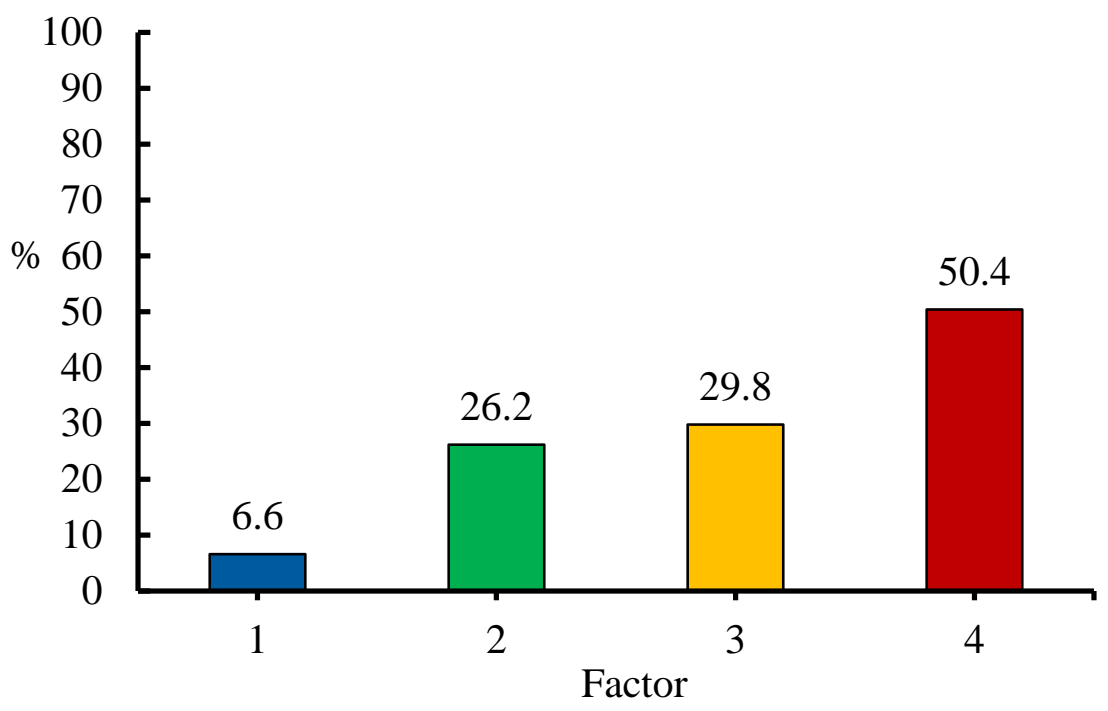

Figure 11. The influence of the pressing force of the rail with the fastener KPP-5 on the under-rail support: 1 - number of assembly-dismantling cycles of the terminal; 2 - terminal weakening; 3 - the location of the axis of the holes and grooves of the anchor; 4 - wear of the gasket.

The total estimated reduction in the pressing force of the rail on the under-rail basis during $\mathrm{T}=0-800$ million $\mathrm{t}$. gross passage is shown in Figure 12 .

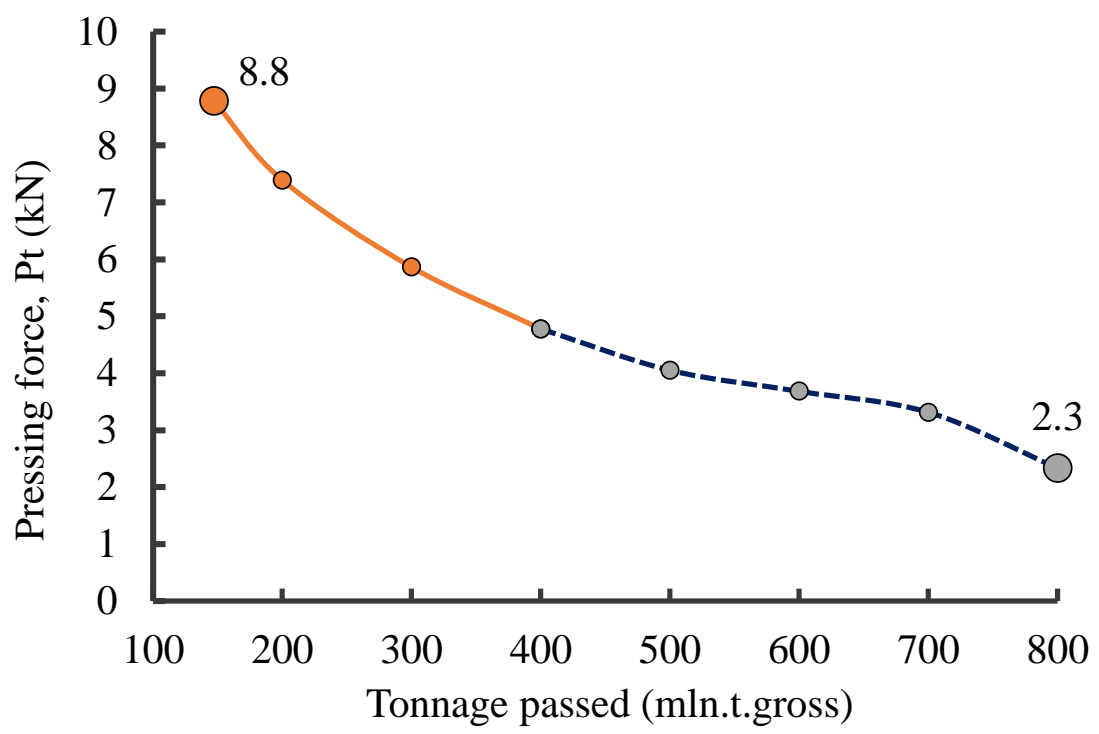

Figure 12. Change in the pressing force of the rail with KPP-5 fastener on the under-rail basis.

Analysing the power work of KPP-5 fastener, it was established that the minimum clamping force of the terminal is $11.5 \mathrm{kN}$. According to the regulatory documentation, this is more than the minimal permissible value $(10 \mathrm{kN})$. According to [11], the rails of equalising sections are allowed to be fastened to the reinforced concrete sleepers with fasteners of sufficient resistance to the longitudinal movement of the rails, which is 25- 
$30 \mathrm{kN} / \mathrm{m}$. Based on the data obtained above, the possible reduction in the linear resistance of the rail line to longitudinal displacement was determined empirically. The change in linear resistance of the rail line with fastener KPP-5 to the longitudinal displacement is shown in Figure 13. According to Figure 13, it has been determined that the resistance value of the rail line to the longitudinal displacement is not ensured starting from $T=100$ million tons, mainly due to the intensive wear of the under-rail gasket (Figure 9).

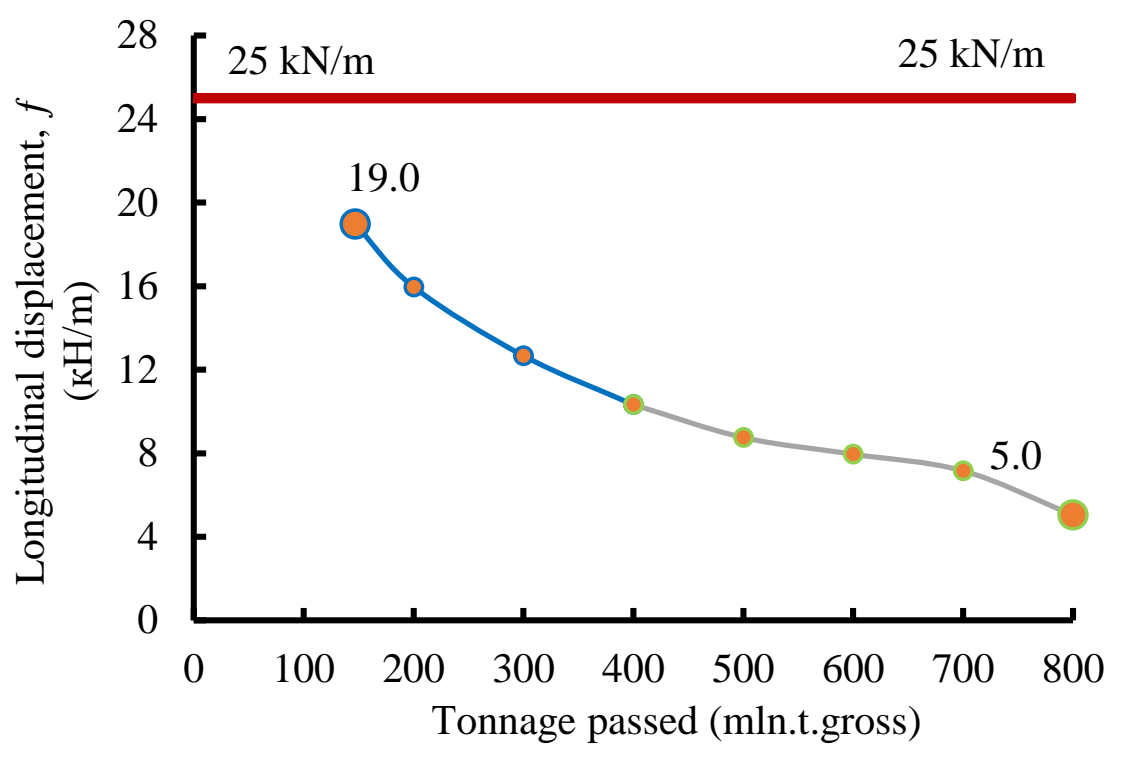

Figure 13. Change in the resistance force of the rail line to the longitudinal displacement depending the tonnage passed.

\section{RESULTS AND DISCUSSION}

To date, the reason for the intensive decrease in the power work of KPP-5 fastener is attributed to the low quality of elastic terminals manufacture that led to the loss of elastic properties and weakening of the fastener. In order to verify such assumptions, the DNURT carried out the research, which is based on the investigation of power work of KPP-5 fastener during operation.

At the initial stages of operation, starting from 100 million tons gross passage, the resistance of the rail to longitudinal displacement is less than the standard value $(25$ $\mathrm{kN} / \mathrm{m}$ ). This is mainly due to the intensive wear of PRP-2.1 under-rail gasket. Therefore, we can say that the reliability of the gasket depends not only on the material it is made of, but also on its design. With regard to the influence of such factor as the location of the axes of the anchor holes relative to the under-rail area of the sleeper is the objective that must be solved at the stage of sleeper manufacture. With a passed tonnage of 447 million tons gross, there were cases of complete non-pressing of the terminal on the insulating insert. It is determined that by the end of the overhaul period with a passed tonnage of 800 million tons gross the pressing force of the terminal on the rail may decrease to 2.3 $\mathrm{kN}$.

It was firstly proposed to use the methodology that would allow thorough investigation and substantiation of the force-work of KPP-5 fastener both at the design stage and under operational conditions. On the basis of this research methodology, the results have been obtained, which allowed formulating recommendations for further improvement of KPP-5 fastener. At the same time, obtained results and practical means 
of monitoring are the basis for the development of regulatory documentation for monitoring and maintenance of the railway track equipped with KPP-5 fastener.

The urgent issue of the present is the development of regulatory documentation on the technology of power work monitoring and railway track maintenance, where KPP5 fastener is used. This is possible when the track is equipped with the device mentioned above, which can determine the elasticity of the terminal and the pressing force of the terminal of KPP-5 fastener on the rail. It improves the reliability of the rail track during the entire overhaul time. This study offers a challenge for its wide use at European railways and open possibilities for its further improvement.

\section{CONCLUSION}

The investigations were carried out using the tracking device for measuring the pressing force of the rail on the support (sleepers). According to the research results, several factors impact the change in pressing force of the rail on the support (sleepers). The main factors are: wear of the under-rail gasket (50.4\%), the location of the axes of the anchor holes relative to the under-rail area of the sleepers (29.8\%), the terminal weakening $(26.2 \%)$ and the terminal assembly- dismantling process $(6.6 \%)$.

The reliability of the power work of KPP-5 fastener can be increased in many ways. For example, with the development of a new terminal design with increased pressing force or a new design of under-rail gasket. For the time being, the authors have been intensively researching the improvement of the under-rail gasket to extend its operating life. Preliminary results obtained by the authors allow increasing the service life of the gasket for 800-1000 million t. of gross passage.

During manufacture of reinforced concrete sleepers of SB-3 type, it is necessary to establish strict monitoring and precision of manufacturing technology of anchor solidification in the sleeper's body. This avoids possible divergences in the centering of axes of the anchor holes relative to the under-rail base of the sleeper.

\section{ACKNOWLEDGEMENT}

The authors are sincerely grateful to the employees of the track facilities of Pridneprovskaya, Odessa, Lvyv and South Western railways for organising and assisting in conducting experimental studies.

\section{REFERENCES}

[1] Nastechik N, Marcul R, Savytskyi V. Elastic deformations impact in elements of the rail fastening, type КПП-5 on a size of pressing force of the rail to the subrail basis. Science and Transport Progress Bulletin of Dnipropetrovsk National University of Railway Transport, pp. 110-120; 2015.

[2] Antolik Ł. Suitability of Rail Gaskets in View of the Requirements Set by EU Standards. Problemy Kolejnictwa. 2011;152:9-19.

[3] Nehoroshev YP, Matvetsov VI. The test results of the fastening SB-3. Track and Track Facilities, pp. 26-27; 2005.

[4] Fink V, Kosenko S. The intermediate rail fastening CAT-5 in Kazakhstan. Science and Transport Progress Bulletin of Dnipropetrovsk National University of Railway Transport, pp. 79-81; 2008. 
[5] Hovorukha VV. Mechanics of deformation and destruction of elastic elements of intermediate rail fasteners. Dnepropetrovsk; 2005.

[6] Afanasev VF. Elastic bindings for wooden and reinforced sleepers. Track and track facilities. 2000:23-6.

[7] Soldatov AA. The effect of rigid terminals design of intermediate fasteners on the work of the track. Bulletin of VNIIZhT, pp. 46-9; 1985.

[8] Kostiuk M, Rybkin V, Bondarenko I, Ivanchenko N. Estimation of parameters of the elastic terminal of mark KP-5.2. Science and Transport Progress Bulletin of Dnipropetrovsk National University of Railway Transport, pp. 11-17; 2003.

[9] Garnham JE, Fletcher DI, Davis CL, Franklin FJ. Visualization and modelling to understand rail rolling contact fatigue cracks in three dimensions. Proceedings of the Institution of Mechanical Engineers, Part F: Journal of Rail and Rapid Transit. 2011;225:165-78.

[10] Rezaie F, Shiri M, Farnam S. Experimental and numerical studies of longitudinal crack control for pre-stressed concrete sleepers. Engineering Failure Analysis. 2012;26:21-30.

[11] Markul R, Kovalchuk V. Investigation of the traffic safety and provision of the performance reliability of the transport infrastructure. In: Technology transfer: fundamental principles and innovative technical solutions. Tallinn, Estonia, pp. $45-7 ; 2017$. 